\title{
COMPORTAMENTO DE LINHAGENS DIAPLÓIDES DE TRIGO EM DOIS LOCAIS DO ESTADO DE SÃO PAULO ${ }^{(1)}$
}

\author{
CARLOS EDUARDO DE OLIVEIRA CAMARGO ${ }^{(2,7)}$; ANTONIO WILSON PENTEADO FERREIRA FILHO(2); \\ LUÍS CARLOS DA SILVA RAMOS ${ }^{(3)}$; ARMANDO PETTINELLI JUNIOR ${ }^{(4)}$; JAIRO LOPES DE CASTRO ${ }^{(5)}$; \\ JOÃO CARLOS FELICIO ${ }^{(2)}$; MARCUS VINICIUS SALOMON ${ }^{(6)}$; JÚLIO CESAR MISTRO ${ }^{(6)}$
}

\begin{abstract}
RESUMO
Compararam-se 20 genótipos (18 linhagens diaplóides e as cultivares IAC-24 e IAC-289) de trigo em experimentos instalados em condição de sequeiro e solo ácido de Capão Bonito (1997-1999), e em condição de irrigação por aspersão e solo ácido com aplicação de calcário de Tatuí (1997-2000). Analisaram-se produção de grãos, outros componentes da produção, características agronômicas e resistência às doenças. Estudou-se também a tolerância ao alumínio em soluções nutritivas, em laboratório. As linhagens diaplóides 10 e 11 e a cultivar IAC-24, em Capão Bonito, e a cultivar IAC-24 e a linhagem diaplóide 19, em Tatuí, destacaram-se quanto à produção de grãos. A linhagem diaplóide 5 foi resistente ao acamamento, a 20 apresentou porte baixo e ciclo precoce para maturar, e a cultivar IAC-289 exibiu maior número de espiguetas por espiga e grãos mais pesados. Todos os genótipos avaliados mostraram-se suscetíveis à mancha-da-folha. Em relação à ferrugem-da-folha, todas as linhagens foram resistentes, exceto a 20 que foi moderadamente resistente. A cultivar IAC-24 e todas as linhagens diaplóides avaliadas apresentaram-se tolerantes à toxicidade de alumínio. Os genótipos mais produtivos em solo ácido e em cultivo de sequeiro apresentaram-se associados às plantas altas, com espigas compridas, maior número de grãos por espiga e por espigueta e tolerância ao alumínio. Em solo ácido, com aplicação de calcário e condição de irrigação por aspersão, os genótipos mais produtivos estavam associados às plantas altas (porte semi-anão) com os grãos pesados, não se correlacionando com a tolerância ao alumínio.
\end{abstract}

Palavras-chave: Triticum aestivum L., linhagens diaplóides, características agronômicas, resistência às doenças, tolerância ao alumínio.

\section{ABSTRACT \\ PERFORMANCE OF WHEAT DIHAPLOID LINES AT TWO LOCATIONS OF THE STATE OF SÃO PAULO, BRAZIL}

Twenty wheat genotypes (18 dihaploid lines and the IAC-24 and IAC-289 cultivars) were evaluated in experiments carried out under dryland and acid soil conditions in Capão Bonito (1997-99), and under sprinkler irrigation and acid soil conditions with lime application in Tatuí (1997-2000). Grain yield, yield

( $\left.{ }^{1}\right)$ Trabalho parcialmente financiado pela FAPESP. Apresentado no I Congresso Brasileiro de Melhoramento de Plantas, realizado em Goiânia (GO) em 2001. Recebido para publicação em 24 de janeiro e aceito em 9 de maio de 2003.

$\left({ }^{2}\right)$ Centro de Análise e Pesquisa Tecnológica do Agronegócio de Grãos e Fibras, Instituto Agronômico (IAC), Caixa Postal 28, 13001-970 Campinas (SP). E-mail: ccamargo@iac.sp.gov.br

$\left({ }^{3}\right)$ Centro de Recursos Genéticos Vegetais, Instituto Agronômico (IAC).

$\left({ }^{4}\right)$ Unidade de Pesquisa do Desenvolvimento de Tatuí, Caixa Postal 33, 18270-000 Tatuí (SP).

$\left(^{5}\right)$ Pólo Regional de Desenvolvimento Tecnológico dos Agronegócios do Sudoeste Paulista,Caixa Postal 62, 18300-970 Capão Bonito(SP).

${ }^{6}$ ) Bolsista de mestrado da FAPESP.

( ${ }^{7}$ Com bolsa de produtividade científica do CNPq. 


\begin{abstract}
components, agronomic characteristics and disease resistance were analyzed. In addition, the genotypes were evaluated for their tolerance to Al toxicity, in nutrient solutions, at laboratory conditions. The dihaploid lines 10 and 11 and the cultivar IAC-24, in Capão Bonito, and the cultivar IAC-24 and the dihaploid line 19, in Tatuí, were superior for grain yield. The dihaploid line 5 presented lodging resistance, the line 20 showed short stature and early plants to mature, and the cultivar IAC-289 exhibited higher number of spikelets per spike and heavier grains. All evaluated genotypes were susceptible to leaf spot. In relation to leaf rust, all lines were resistant, except the line 20 which was moderately resistant. The cultivar IAC-24 and all evaluated dihaploid lines were tolerant to aluminum toxicity. The higher grain yield genotypes, under dryland and acid soil conditions, were associated to tall plants, with long spikes, with high number of grains per spike and per spikelet and with tolerance to aluminum. Under sprinkler irrigation and acid soil conditions with lime application the most productive genotypes were associated to tall plants (semidwarf type) with heavy grains, and presenting no correlation with tolerance to aluminum.
\end{abstract}

Key words: Triticum aestivum L., dihaploid lines, grain yield, agronomic characteristics, tolerance to aluminum toxicity.

\section{INTRODUÇÃO}

O atual consumo de grãos de trigo no Brasil é de 10 milhões de toneladas, e a produção de trigo nacional representa apenas $20 \%$ a $25 \%$ do que se consome no mercado interno, em virtude de aspectos agronômicos, tecnológicos e político-econômicos.

O programa de melhoramento genético de trigo do Instituto Agronômico (IAC) tem procurado desenvolver cultivares de porte semi-anão, de alto potencial produtivo e com tolerância à toxicidade de alumínio, mediante cruzamentos entre cultivares nacionais adaptados às condições de solo ácido e cultivares semi-anões introduzidos do Centro Internacional de Melhoramento de Milho e Trigo (CIMMYT), México (CAMARgo et al., 2001; 1996).

O programa de melhoramento genético de trigo tradicional despende muitos anos de intenso trabalho, em condição de campo, onde as plantas são selecionadas a partir de populações segregantes para se obter uniformidade genética. Por outro lado, é possível reduzir substancialmente o tempo despendido, utilizando-se a técnica da cultura de antera "in vitro". Com essa técnica, obtêm-se plantas haplóides, que se podem tornar férteis com a duplicação do número de cromossomos utilizando-se a colchicina. As plantas obtidas com base nesse tratamento apresentam $100 \%$ de homozigose, sendo convencionalmente consideradas diaplóides (DH). Essa técnica é muito valiosa nos programas de melhoramento genético, visto que a homozigose é alcançada em apenas uma geração (Grando e Moraes-Fernandes, 1997; Camargo et al., 2001; SALOMON et al., 2003).

Outra vantagem da técnica de cultura de anteras é diminuir a possibilidade de perda de recombinantes (plantas de porte baixo, por exemplo), o que é difícil de ser alcançado com o processo tradicional, consideran- do a segregação gênica nas gerações de seleção (as plantas de porte baixo poderiam ser prejudicadas pela competição com as plantas de porte médio ou alto). Linhagens diaplóides apresentando plantas de porte baixo $(50-53 \mathrm{~cm})$ foram obtidas e avaliadas com sucesso em diferentes locais do Estado de São Paulo no período de 1994 a 1996 (RAmos et al., 2000).

A técnica da cultura de anteras foi recentemente incorporada no programa de melhoramento genético de trigo do IAC a partir de plantas híbridas, em geração $F_{1}$.

Após a adaptação da técnica (RAmos et al., 1994), as primeiras linhagens DH foram obtidas e avaliadas em experimentos em condição de campo, revelando resultados promissores. A técnica foi utilizada em outros cruzamentos, especialmente quando, pelo menos, um dos parentais apresentava alta capacidade androgênica.

O objetivo deste trabalho foi avaliar as linhagens $\mathrm{DH}$ oriundas de hibridações entre as cultivares CIANO 79, introduzido do CIMMYT, México e IAC24, em comparação com cultivares-controle, em experimentos instalados em dois locais paulistas.

\section{MATERIAL E MÉTODOS}

Os experimentos foram instalados em dois locais do Estado de São Paulo: Capão Bonito, em condição de sequeiro e solo ácido, no período de 1997 a 1999, e Tatuí, em condição de irrigação por aspersão e solo corrigido, durante o período de 1997-2000, para avaliar 20 genótipos, sendo 18 linhagens diaplóides, obtidas via cultura de anteras in vitro, conforme RAmOs et al. (1994), e dois cultivares-controle (Quadro 1). 
Quadro 1. Produção média de grãos, altura média das plantas, acamamento e ciclo da emergência à maturação, dos 20 genótipos de trigo avaliados nos experimentos instalados em Capão Bonito (1997-1999) e Tatuí (1997-2000)

\begin{tabular}{|c|c|c|c|c|c|c|c|c|c|c|}
\hline \multirow[b]{2}{*}{ Tratamento } & \multirow{2}{*}{\multicolumn{3}{|c|}{ Cruzamento }} & \multicolumn{4}{|c|}{ Capão Bonito } & \multicolumn{3}{|c|}{ Tatuí } \\
\hline & & & & $\begin{array}{c}\text { Produção } \\
\text { de grãos }\end{array}$ & $\begin{array}{c}\text { Altura } \\
\text { de plantas }\end{array}$ & $\begin{array}{c}\text { Acama- } \\
\text { mento }\end{array}$ & $\begin{array}{l}\text { Ciclo da emergências } \\
\text { à maturação }\end{array}$ & $\begin{array}{c}\text { Produção } \\
\text { de grãos }\end{array}$ & $\begin{array}{c}\text { Altura } \\
\text { de plantas }\end{array}$ & $\begin{array}{c}\text { Acama- } \\
\text { mento }\end{array}$ \\
\hline & & & & kg.ha-1 & $\mathrm{cm}$ & $\%$ & dias & $\mathrm{kg} \cdot \mathrm{ha}^{-1}$ & $\mathrm{~cm}$ & $\%$ \\
\hline 1 & IAC - 24 & & & 1969 a & $70 \quad \mathrm{a}$ & 13 & $140 \mathrm{a}$ & $3290 \quad a$ & 81 a & 18 \\
\hline 2 & IAC-289 & & & $1274 \mathrm{~b}$ & $63 a-c$ & 20 & $141 \mathrm{a}$ & 3128 a-c & 81 a & 3 \\
\hline 3 & CIANO 79 & $x$ & IAC - 24 & $1519 \mathrm{ab}$ & $68 \mathrm{a}-\mathrm{c}$ & 7 & $137 \mathrm{ab}$ & 2554 bc & $76 \mathrm{ab}$ & 8 \\
\hline 4 & CIANO 79 & $x$ & IAC - 24 & $1815 \mathrm{ab}$ & $68 \mathrm{a}-\mathrm{c}$ & 7 & $135 \mathrm{ab}$ & 2786 a-c & $76 \mathrm{ab}$ & 5 \\
\hline 5 & CIANO 79 & $x$ & IAC - 24 & $1903 \mathrm{ab}$ & $69 \mathrm{ab}$ & 0 & $137 \mathrm{ab}$ & $2517 \quad c$ & $75 \mathrm{bc}$ & 0 \\
\hline 6 & CIANO 79 & $x$ & IAC - 24 & $1681 \mathrm{ab}$ & $67 \mathrm{a}-\mathrm{c}$ & 13 & $136 \mathrm{ab}$ & 2698 a-c & $75 \mathrm{bc}$ & 3 \\
\hline 7 & CIANO 79 & $x$ & IAC - 24 & $1832 a b$ & $68 \mathrm{a}-\mathrm{c}$ & 0 & $136 \mathrm{ab}$ & 2611 a-c & $74 \mathrm{~cd}$ & 3 \\
\hline 8 & CIANO 79 & $x$ & IAC - 24 & $1578 \mathrm{ab}$ & $67 \mathrm{a}-\mathrm{c}$ & 7 & $135 \mathrm{ab}$ & 2686 a-c & $75 \mathrm{bc}$ & 5 \\
\hline 9 & CIANO 79 & $X$ & IAC - 24 & $1690 \mathrm{ab}$ & $67 \mathrm{a}-\mathrm{c}$ & 13 & $134 \mathrm{ab}$ & 2825 a-c & $75 \mathrm{bc}$ & 0 \\
\hline 10 & CIANO 79 & $x$ & IAC - 24 & 1994 a & $69 \mathrm{ab}$ & 7 & $137 \mathrm{ab}$ & $2710 a-c$ & $75 \mathrm{bc}$ & 8 \\
\hline 11 & CIANO 79 & $x$ & IAC - 24 & 1991 a & $68 \mathrm{a}-\mathrm{c}$ & 7 & $140 \mathrm{a}$ & 2769 a-c & $75 \mathrm{bc}$ & 5 \\
\hline 12 & CIANO 79 & $x$ & IAC - 24 & $1800 \mathrm{ab}$ & $65 a-c$ & 0 & $135 \mathrm{ab}$ & 2674 a-c & $76 \mathrm{ab}$ & 5 \\
\hline 13 & CIANO 79 & $x$ & IAC - 24 & $1859 a b$ & $65 \mathrm{a}-\mathrm{c}$ & 7 & $134 \mathrm{ab}$ & 2694 a-c & $75 \mathrm{bc}$ & 8 \\
\hline 14 & CIANO 79 & $x$ & IAC - 24 & $1822 \mathrm{ab}$ & 65 a-c & 13 & $137 \mathrm{ab}$ & 2705 a-c & $75 \mathrm{bc}$ & 8 \\
\hline 15 & IAC - 24 & $x$ & CIANO 79 & $1797 \mathrm{ab}$ & $67 \mathrm{a}-\mathrm{c}$ & 7 & $136 \mathrm{ab}$ & 2995 a-c & $75 \mathrm{bc}$ & 8 \\
\hline 16 & IAC - 24 & $x$ & CIANO 79 & $1711 \mathrm{ab}$ & $68 \mathrm{a}-\mathrm{c}$ & 7 & $135 \mathrm{ab}$ & 2783 a-c & $76 \mathrm{ab}$ & 8 \\
\hline 17 & IAC - 24 & $x$ & CIANO 79 & $1701 \mathrm{ab}$ & $65 a-c$ & 13 & $135 \mathrm{ab}$ & 2861 a-c & $75 \mathrm{bc}$ & 5 \\
\hline 18 & IAC - 24 & $x$ & CIANO 79 & $1804 \mathrm{ab}$ & $66 \mathrm{a}-\mathrm{c}$ & 13 & $135 \mathrm{ab}$ & $2521 \mathrm{c}$ & $74 \mathrm{~cd}$ & 0 \\
\hline 19 & CIANO 79 & $x$ & IAC - 24 & $1368 \mathrm{ab}$ & $58 \mathrm{c}$ & 7 & $129 \mathrm{~b}$ & $3236 \mathrm{ab}$ & $71 \mathrm{~cd}$ & 10 \\
\hline 20 & CIANO 79 & $x$ & IAC - 24 & $1363 \mathrm{ab}$ & $60 \mathrm{bc}$ & 13 & $127 \mathrm{~b}$ & 2821 a-c & $69 \mathrm{~d}$ & 5 \\
\hline F (Anos) & & & & $50,20^{*}$ & $61,98^{*}$ & - & $96,84^{*}$ & $80,83^{*}$ & $165,87^{*}$ & - \\
\hline F(Genótipos) & & & & $2,69^{*}$ & $2,32 *$ & - & $2,32 *$ & $2,72 *$ & $5,72 *$ & - \\
\hline$F(G \times A)$ & & & & 1,04 & 1,60 & - & $2,28^{*}$ & 1,07 & 1,57 & - \\
\hline d.m.s. & & & & 685 & 11 & - & 11 & 694 & 6 & - \\
\hline C.V.( $\%)$ & & & & 25,11 & 8,40 & - & 3,52 & 18,30 & 4,60 & - \\
\hline
\end{tabular}


Nos experimentos de campo, usou-se o delineamento experimental de blocos ao acaso, com quatro repetições por local. O experimento constituiu-se de 80 parcelas, cada uma delas formadas por seis linhas de $3 \mathrm{~m}$ de comprimento, espaçadas de $0,20 \mathrm{~m}$ e separadas, lateralmente, por $0,60 \mathrm{~m}$. A semeadura foi feita à base de 80 sementes por metro de sulco, equivalendo a 1.440 sementes por parcela, com área útil de colheita de $3,6 \mathrm{~m}^{2}$.

Coletaram-se os seguintes dados nos experimentos: presença de mancha-da-folha (Bipolaris sorokiniana) e de ferrugem-da-folha (Puccinia triticina), com exceção dos experimentos semeados em 1997; ciclo da emergência à maturação; ocorrência de acamamento; altura das plantas e produção de grãos. Para determinar o comprimento da espiga, do número de espiguetas por espiga, do número de grãos por espiga e por espigueta e da massa de cem grãos, colheram-se dez espigas de cada parcela, apenas nos experimentos de Capão Bonito em 1998 e de Tatuí em 1997 e 1998. A avaliação dessas características foi feita conforme Schramm et al. (1974), Мента (1978) e CAMARgo et al. (1995).

Os dados de produção de grãos, altura das plantas, comprimento da espiga, número de espiguetas por espiga, número de grãos por espiga e por espigueta e massa de cem grãos de cada experimento foram inicialmente submetidos às análises individuais da variância. Efetuou-se, posteriormente, a análise conjunta da variância para produção de grãos e altura das plantas, nos experimentos instalados em Tatuí e Capão Bonito, a fim de avaliar a ocorrência da interação dos genótipos com os anos em cada local. O mesmo procedimento foi seguido para os dados de comprimento da espiga, do número de espiguetas por espiga, do número de grãos por espiga e por espigueta e da massa de cem grãos, nos experimentos de Tatuí em 1997/1998. Para a comparação das médias dos genótipos, utilizou-se o teste de Tukey ao nível de 5\%.

Correlações simples entre as produções médias de grãos de cada genótipo e os respectivos comprimentos da espiga, números de espiguetas por espiga, números de grãos por espiga e por espigueta e massas de cem grãos foram estimadas para Tatuí, considerando-se os dados médios dos anos de 1997 e 1998, e para Capão Bonito empregando-se os dados de 1998.

As plântulas dos 20 genótipos e das cultivares-controle BH-1146 (tolerante) e Anahuac (sensível) foram testadas para a tolerância ao alumínio, em condição de laboratório, nas doses de $0,2,4,6,8$ e 10 $\mathrm{mg} . \mathrm{L}^{-1}$ de $\mathrm{Al}^{3+}$, em soluções nutritivas, conforme Camargo (1984) e Moore et al. (1976).
O delineamento experimental foi o de blocos ao acaso, com arranjo em parcelas subdivididas: as parcelas, compostas por seis concentrações de alumínio e, as subparcelas, pelos genótipos de trigo. Realizaram-se duas repetições para cada solução-tratamento. $\mathrm{Na}$ análise dos dados, considerou-se a média de comprimento da raiz primária central das dez plantas de cada genótipo, para cada repetição.

Os genótipos que apresentaram crescimento radicular foram considerados tolerantes, enquanto aqueles que não mostraram crescimento das raízes foram considerados sensíveis, após 72 horas de crescimento nas soluções nutritivas completas sem alumínio, que se seguiu a 48 horas de crescimento nas soluções de tratamento contendo cinco diferentes concentrações de alumínio.

Calcularam-se correlações simples para os experimentos instalados em Tatuí (1997-2000) e Capão Bonito (1997-1999), entre as produções médias de grãos dos 20 genótipos nesse período e os crescimentos médios das raízes dos genótipos, medidos após 72 horas de crescimento na solução nutritiva, que se seguiu ao da solução-tratamento contendo $2,4,6,8$ e $10 \mathrm{mg} \cdot \mathrm{L}^{-1}$ de $\mathrm{Al}^{3+}$.

\section{RESULTADOS E DISCUSSÃO}

Os quadrados médios das análises de variância individual das produções de grãos dos genótipos (linhagens diaplóides e cultivares) de trigo, estudados nos experimentos de Tatuí e Capão Bonito em 1997, 1998, 1999, e Tatuí, em 2000, mostraram efeitos significativos para genótipos, com exceção do de Tatuí (2000) e Capão Bonito (1998), e não significativos para repetições.

Os quadrados médios da análise conjunta da variância das produções médias dos genótipos dos experimentos de Capão Bonito (1997-1999), instalados em condição de sequeiro e de solo ácido, revelaram efeitos significativos para experimentos e genótipos e não significativos para a interação genótipos $x$ anos (Quadro 1).

Para a comparação das médias de produção de grãos dos tratamentos dos três experimentos de Capão Bonito, mediante teste de Tukey, verificou-se que as linhagens diaplóides $10\left(1.994 \mathrm{~kg} \cdot \mathrm{ha}^{-1}\right)$ e 11 (1.991 kg.ha-1) e a cultivar IAC-24 (1.969 kg.ha-1) foram os mais produtivos, diferindo, porém, somente da cultivar-controle IAC-289 (1.274 kg.ha $\left.{ }^{-1}\right)$, sensível à toxicidade de alumínio. Deve-se considerar que o método de obtenção dessas linhagens, adaptadas às condições de solo ácido de Capão Bonito, mediante duplicação de plantas haplóides, originárias de cultura 
de anteras de plantas híbridas $\mathrm{F}_{1}$, permitiu um ganho de, pelo menos, cinco anos em relação ao método convencional de melhoramento adotado pelo Instituto Agronômico (CAMARgo, 1993).

Os quadrados médios da análise da variância conjunta das produções médias de grãos dos genótipos dos experimentos em condição de solo corrigido e com irrigação por aspersão, em Tatuí, apresentaram efeitos significativos para experimentos (anos) e genótipos, porém os efeitos da interação genótipos com anos não foram significativos (Quadro 1).

Aplicando-se o teste de Tukey para a comparação das médias de produção de grãos, nos quatro experimentos de Tatuí, observou-se que a cultivar IAC24 produziu $3.290 \mathrm{~kg} \cdot \mathrm{ha}^{-1}$, sendo a mais produtiva, diferindo somente das linhagens diaplóides 3 (2.554 kg.ha $\left.{ }^{-1}\right), 5\left(2.517 \mathrm{~kg} \cdot \mathrm{ha}^{-1}\right)$ e $18\left(2.521 \mathrm{~kg} \cdot \mathrm{ha}^{-1}\right)$ ao nível de 5\%. Destacou-se também a linhagem 19 (3.236 $\left.\mathrm{kg} \cdot \mathrm{ha}^{-1}\right)$, quanto à produção de grãos nessas condições.

Os quadrados médios da análise da variância conjunta das alturas das plantas dos genótipos avaliados nos experimentos de Capão Bonito e Tatuí, separadamente, exibiram efeitos significativos para anos e genótipos, e não significativos para a interação genótipos com anos (Quadro 1).

A cultivar IAC-24 apresentou as plantas mais altas, nos experimentos de Capão Bonito, diferindo significativamente somente das linhagens diaplóides 19 e 20, que tiveram o porte de planta mais baixo entre os genótipos estudados. Observando-se a altura média das plantas dos genótipos, nos quatro experimentos de Tatuí, verificou-se que as cultivares IAC-24 e IAC-289 exibiram as plantas mais altas, não diferindo porém, das linhagens diaplóides 3, 4, 12 e 16 .

A linhagem diaplóide 20 exibiu as plantas mais baixas, somente não diferindo das linhagens 7 , 18 e 19. Verificou-se baixa incidência de plantas acamadas em todos os experimentos considerados, em grande parte devido ao porte semi-anão dos genótipos avaliados, com altura de plantas variando de 58 a 70 cm, em Capão Bonito, e de 69 a 81 cm, em Tatuí. Apesar desse fato, pode-se destacar a linhagem diaplóide 5 por mostrar resistência ao acamamento (nenhuma planta acamada) nos experimentos instalados nos dois locais.

Os ciclos médios, em dias, da emergência à maturação dos genótipos estudados nos experimentos de Capão Bonito encontram-se no quadro 1: IAC-24, IAC-289 e a linhagem diaplóide 11 foram as mais tardias, diferindo significativamente das linhagens 19 e 20, as mais precoces. A linhagem diaplóide 20 que apresenta, ao mesmo tempo, plantas de porte baixo e de ciclo precoce, revela um germoplasma de valor como fonte genética dessas características, no programa de cruzamentos do Instituto Agronômico.

Os graus médios de infecção de mancha-dafolha e ferrugem-da-folha, nos genótipos avaliados nos experimentos semeados em Capão Bonito (19981999) e Tatuí (1998-2000), são apresentados no quadro 2. Verificou-se que os graus médios de infecção de mancha-da-folha foram mais elevados em Capão Bonito, onde as condições mostraram-se mais favoráveis ao desenvolvimento do patógeno.

Empregando-se a escala proposta por MeHTA (1978), as linhagens 9, 11 e 19 e as cultivares IAC-24, IAC-289 foram classificadas como suscetíveis, manifestando uma porcentagem de área foliar infectada entre 25 e 50, em, pelo menos, um experimento.

Os demais genótipos revelaram-se altamente suscetíveis aos agentes causais das manchas foliares, com uma porcentagem de área foliar infectada entre 51 e 99 em, pelo menos, um dos experimentos avaliados. Esses resultados eram esperados, considerando-se que as 18 linhagens diaplóides avaliadas originaramse do cruzamento entre a cultivar de trigo IAC-24 e a linhagem mexicana CIANO 79, ambas suscetíveis ao agente causal das manchas foliares (CAMARGO, 1993; Camargo e Ferreira Filho, 2000).

Em relação à ferrugem-da-folha, todas as linhagens diaplóides comportaram-se como resistentes, ou seja, apresentaram um grau de infecção entre $1 \mathrm{e}$ $5 \mathrm{~S}$, exceto a linhagem 20 , que foi moderadamente resistente, exibindo um grau de infecção de $15 S$.

As cultivares IAC-24 e IAC-289 foram consideradas suscetíveis ao agente causal da ferrugem-da-folha, por mostrarem um grau de infecção entre 26 e $50 \mathrm{~S}$ em, pelo menos, um dos experimentos. A linhagem CIANO 79 foi eficiente em transmitir para seus descendentes, por meio de cruzamentos, a resistência genética a essa doença.

Os quadrados médios das análises da variância para comprimento da espiga, número de espiguetas por espiga, números de grãos por espiga e por espigueta e massa de cem grãos do experimento de Capão Bonito (1998) foram significativos para genótipos, com exceção da massa de cem grãos (Quadro 3).

As linhagens diaplóides 11, 12 e 14 e a cultivar IAC-289 apresentaram as espigas mais compridas, diferindo, porém, apenas da linhagem 19 , com as mais curtas. A cultivar IAC-289 apresentou o maior valor em relação ao número de espiguetas por espiga, mas diferindo, apenas, das linhagens 19 e 20. A linhagem 14 revelou o maior número de grão por espiga diferindo, somente, da linhagem 19. 
Quadro 2. Graus médios de infecção $\left(^{1}\right)$ de mancha-da-folha e ferrugem-da-folha dos 20 genótipos de trigo avaliados em Capão Bonito (1998-1999) e Tatuî $(1998-2000)$

\begin{tabular}{|c|c|c|c|c|c|c|c|c|c|c|c|c|c|c|c|}
\hline & & & & & & ncha-do & folha & & & & & rugem & folha & & \\
\hline Tra & ento & Izam & & Cap & Bonito & & & & & Capã & Bonito & & & & \\
\hline & & & & 1998 & 1999 & 1998 & 1999 & 2000 & Média & 1998 & 1999 & 1998 & 1999 & 2000 & Média \\
\hline 1 & IAC-24 & & & 20 & 40 & 20 & 8 & 20 & 22 & $\mathrm{t} S$ & $20 \mathrm{~S}$ & $20 \mathrm{~S}$ & $30 \mathrm{~S}$ & $20 S$ & $18 \mathrm{~S}$ \\
\hline 2 & IAC-289 & & & 20 & 40 & 30 & 15 & 10 & 23 & 0 & 0 & $20 \mathrm{~S}$ & $40 \mathrm{~S}$ & $20 \mathrm{~S}$ & $16 \mathrm{~S}$ \\
\hline 3 & CIANO 79 & $x$ & IAC - 24 & 30 & 60 & 30 & 8 & 10 & 28 & 0 & 0 & 0 & tS & tS & tS \\
\hline 4 & CIANO 79 & $x$ & IAC - 24 & 20 & 60 & 30 & 10 & 30 & 30 & 0 & 0 & 0 & tS & 0 & $\mathrm{tS}$ \\
\hline 5 & CIANO 79 & $x$ & IAC - 24 & 30 & 60 & 40 & 10 & 20 & 32 & 0 & 0 & 0 & $5 S$ & 0 & $\mathrm{t} S$ \\
\hline 6 & CIANO 79 & $x$ & IAC - 24 & 20 & 60 & 30 & 8 & 5 & 25 & 0 & 0 & 0 & tS & tS & tS \\
\hline 7 & CIANO 79 & $x$ & IAC - 24 & 30 & 60 & 40 & 15 & 20 & 33 & 0 & 0 & 0 & $3 S$ & $\mathrm{t} S$ & tS \\
\hline 8 & CIANO 79 & $x$ & IAC - 24 & 20 & 60 & 30 & 10 & 5 & 25 & 0 & 0 & 0 & $3 S$ & 0 & $\mathrm{t} S$ \\
\hline 9 & CIANO 79 & $x$ & IAC - 24 & 30 & 50 & 30 & 10 & 10 & 26 & 0 & 0 & $5 S$ & tS & 0 & tS \\
\hline 10 & CIANO 79 & $x$ & IAC - 24 & 20 & 60 & 40 & 10 & 10 & 28 & 0 & 0 & 0 & $5 S$ & 0 & $\mathrm{tS}$ \\
\hline 11 & CIANO 79 & $x$ & IAC - 24 & 20 & 50 & 30 & 10 & 10 & 24 & 0 & 0 & 0 & $3 S$ & 0 & $\mathrm{tS}$ \\
\hline 12 & CIANO 79 & $x$ & IAC - 24 & 20 & 60 & 30 & 10 & 20 & 28 & 0 & 0 & 0 & $3 S$ & 0 & $\mathrm{tS}$ \\
\hline 13 & CIANO 79 & $x$ & IAC - 24 & 30 & 60 & 40 & 10 & 5 & 29 & 0 & 0 & 0 & $3 S$ & 0 & $\mathrm{tS}$ \\
\hline 14 & CIANO 79 & $x$ & IAC - 24 & 20 & 60 & 40 & 10 & 10 & 28 & 0 & 0 & 0 & $3 S$ & tS & $\mathrm{tS}$ \\
\hline 15 & IAC - 24 & $x$ & CIANO 79 & 20 & 60 & 30 & 10 & 10 & 26 & 0 & 0 & 0 & $3 S$ & 0 & $\mathrm{t} S$ \\
\hline 16 & IAC - 24 & $x$ & CIANO 79 & 30 & 60 & 30 & 10 & 10 & 28 & 0 & 0 & $\mathrm{tS}$ & $3 S$ & 0 & $\mathrm{tS}$ \\
\hline 17 & IAC - 24 & $x$ & CIANO 79 & 20 & 60 & 30 & 8 & 30 & 30 & 0 & 0 & $5 S$ & $5 S$ & 0 & $2 S$ \\
\hline 18 & IAC - 24 & $x$ & CIANO 79 & 30 & 60 & 30 & 15 & 10 & 29 & 0 & 0 & 0 & $5 S$ & 0 & $\mathrm{tS}$ \\
\hline 19 & CIANO 79 & $x$ & IAC -24 & 30 & 50 & 30 & 10 & 20 & 28 & 0 & 0 & $5 S$ & $5 S$ & $5 S$ & $3 S$ \\
\hline 20 & CIANO 79 & $x$ & IAC - 24 & 40 & 60 & 30 & 10 & 20 & 32 & 0 & 0 & $5 S$ & $15 S$ & $5 S$ & $5 S$ \\
\hline
\end{tabular}

(1) Avaliação de ferrugem-da-folha segundo Schramm et. al. (1974) e mancha-da-folha segundo Mehta (1978): $0=$ imune; $\mathrm{t}$ a 5\% de área infectada = resistente; $6 \%$ a $25 \%=$ moderadamente resistente; $26 \%$ a $50 \%=$ suscetível, e $51 \%$ a $99 \%=$ altamente suscetível; $t=$ traço (apenas algumas pústulas); $\mathrm{S}=$ reação de suscetibilidade. 
Quadro 3. Dados médios referentes ao comprimento da espiga, número de espiguetas por espiga, número de grãos por espiga e por espigueta e massa de cem grãos dos 20 genótipos de trigo avaliados nos experimentos instalados em Capão Bonito (1998) e Tatuí (1997-98).

\begin{tabular}{|c|c|c|c|c|c|c|c|c|c|c|c|c|c|}
\hline & & & & & Capã & nito & & & & & & & \\
\hline Tratatamento & & Cruzam & & Comprimento & Espiguetas/ & Grãos/ & Grãos/ & Massa de & Comprimento & Espiguetas/ & Grãos/ & Grãos/ & Massa de \\
\hline & & & & $\mathrm{m}$ & & & & $\mathrm{g}$ & $\mathrm{cm}$ & & & & $\mathrm{g}$ \\
\hline 1 & IAC - 24 & & & $7,5 \mathrm{ab}$ & $16,1 \mathrm{ab}$ & $36,1 \mathrm{ab}$ & $2,26 \mathrm{~b}$ & 3,94 & $7,8 \mathrm{a}-\mathrm{c}$ & $17,1 \mathrm{a}-\mathrm{c}$ & 38,9 & 2,27 & $4,00 \mathrm{ab}$ \\
\hline 2 & IAC - 289 & & & $8,3 \mathrm{a}$ & 17,6 a & $46,9 \mathrm{ab}$ & $2,68 \mathrm{ab}$ & 4,02 & $8,7 \mathrm{a}-\mathrm{c}$ & $19,3 \mathrm{a}$ & 51,1 & 2,59 & $4,06 \mathrm{a}$ \\
\hline 3 & CIANO 79 & $x$ & IAC - 24 & $7,0 \mathrm{ab}$ & $13,3 \mathrm{a}-\mathrm{c}$ & $40,8 \mathrm{ab}$ & $3,10 \mathrm{ab}$ & 3,57 & $8,7 \mathrm{a}-\mathrm{c}$ & 17,0 a-c & 51,7 & 3,04 & $3,43 \mathrm{c}$ \\
\hline 4 & CIANO 79 & $x$ & IAC - 24 & $7,6 \mathrm{ab}$ & $14,7 \mathrm{ab}$ & $47,4 \mathrm{ab}$ & $3,16 \mathrm{ab}$ & 3,42 & $8,4 \mathrm{a}-\mathrm{c}$ & $16,1 \mathrm{bc}$ & 47,9 & 2,93 & $3,54 \mathrm{c}$ \\
\hline 5 & CIANO 79 & $x$ & IAC - 24 & $8,1 \mathrm{ab}$ & $15,6 a b$ & $49,4 \mathrm{ab}$ & $3,14 \mathrm{ab}$ & 3,37 & $8,5 \mathrm{a}-\mathrm{c}$ & $16,0 \mathrm{bc}$ & 50,0 & 3,14 & $3,39 \mathrm{c}$ \\
\hline 6 & CIANO 79 & $x$ & IAC - 24 & $6,3 \mathrm{ab}$ & $13,9 \mathrm{a}-\mathrm{c}$ & $47,2 \mathrm{ab}$ & $3,44 \mathrm{a}$ & 3,70 & $8,9 a$ & $17,4 \mathrm{ab}$ & 52,3 & 3,03 & $3,50 \mathrm{c}$ \\
\hline 7 & CIANO 79 & $x$ & IAC - 24 & $8,0 \mathrm{ab}$ & $14,5 \mathrm{ab}$ & $51,6 \mathrm{ab}$ & $3,57 \mathrm{a}$ & 3,60 & $8,5 \mathrm{a}-\mathrm{c}$ & $16,1 \mathrm{bc}$ & 48,3 & 2,99 & $3,41 \mathrm{c}$ \\
\hline 8 & CIANO 79 & $x$ & IAC - 24 & $7,6 \mathrm{ab}$ & $14,2 \mathrm{a}-\mathrm{c}$ & $44,9 \mathrm{ab}$ & $3,19 \mathrm{ab}$ & 3,56 & $8,7 \mathrm{a}-\mathrm{c}$ & $17,2 \mathrm{a}-\mathrm{c}$ & 51,0 & 2,94 & $3,54 \mathrm{c}$ \\
\hline 9 & CIANO 79 & $x$ & IAC - 24 & $7,1 \mathrm{ab}$ & $13,3 \mathrm{a}-\mathrm{c}$ & $43,0 \mathrm{ab}$ & $3,22 \mathrm{ab}$ & 3,76 & $8,4 \mathrm{a}-\mathrm{c}$ & $16,3 \mathrm{a}-\mathrm{c}$ & 46,9 & 2,87 & $3,51 \mathrm{c}$ \\
\hline 10 & CIANO 79 & $x$ & IAC - 24 & $8,3 \mathrm{ab}$ & $15,0 \mathrm{ab}$ & $45,5 \mathrm{ab}$ & $3,06 \mathrm{ab}$ & 5,72 & $8,7 \mathrm{a}-\mathrm{c}$ & $17,1 \mathrm{a}-\mathrm{c}$ & 48,7 & 2,82 & $3,41 \mathrm{c}$ \\
\hline 11 & CIANO 79 & $x$ & IAC - 24 & $8,2 \mathrm{a}$ & $15,4 \mathrm{ab}$ & $51,6 \mathrm{ab}$ & $3,37 \mathrm{ab}$ & 3,70 & $8,4 \mathrm{a}-\mathrm{c}$ & $15,8 \mathrm{bc}$ & 47,3 & 2,98 & $3,53 \mathrm{c}$ \\
\hline 12 & CIANO 79 & $x$ & IAC - 24 & $8,3 \mathrm{a}$ & $14,7 \mathrm{ab}$ & $51,3 \mathrm{ab}$ & $3,73 \mathrm{a}$ & 3,60 & $8,7 \mathrm{a}-\mathrm{c}$ & $17,3 \mathrm{a}-\mathrm{c}$ & 50,0 & 2,89 & $3,38 \mathrm{c}$ \\
\hline 13 & CIANO 79 & $x$ & IAC - 24 & $7,7 \mathrm{ab}$ & $13,3 \mathrm{a}-\mathrm{c}$ & $46,9 \mathrm{ab}$ & $3,50 \mathrm{a}$ & 3,46 & $8,4 \mathrm{a}-\mathrm{c}$ & $16,1 \mathrm{bc}$ & 46,6 & 2,88 & $3,46 \mathrm{c}$ \\
\hline 14 & CIANO 79 & $x$ & IAC - 24 & $8,5 \mathrm{a}$ & $15,5 \mathrm{ab}$ & $56,3 \mathrm{a}$ & $3,65 \mathrm{a}$ & 3,65 & $8,9 \mathrm{a}$ & $17,2 \mathrm{a}-\mathrm{c}$ & 51,4 & 2,96 & $3,45 \mathrm{c}$ \\
\hline 15 & IAC - 24 & $x$ & CIANO 79 & $7,5 \mathrm{ab}$ & $13,3 \mathrm{a}-\mathrm{c}$ & $46,3 \mathrm{ab}$ & $3,46 \mathrm{a}$ & 3,62 & $8,2 \mathrm{a}-\mathrm{c}$ & $16,1 \mathrm{bc}$ & 47,1 & 2,90 & $3,55 \mathrm{bc}$ \\
\hline 16 & IAC - 24 & $x$ & CIANO 79 & $7,1 \mathrm{ab}$ & $13,3 \mathrm{a}-\mathrm{c}$ & $41,1 \mathrm{ab}$ & $3,08 \mathrm{ab}$ & 3,43 & $8,5 \mathrm{a}-\mathrm{c}$ & $16,9 \mathrm{a}-\mathrm{c}$ & 47,8 & 2,81 & $3,55 \mathrm{bc}$ \\
\hline 17 & IAC - 24 & $x$ & CIANO 79 & $7,2 \mathrm{ab}$ & $13,2 \mathrm{a}-\mathrm{c}$ & $40,5 \mathrm{ab}$ & $3,06 \mathrm{ab}$ & 3,51 & $8,4 \mathrm{a}-\mathrm{c}$ & $16,4 \mathrm{a}-\mathrm{c}$ & 47,3 & 2,85 & $3,44 \mathrm{c}$ \\
\hline 18 & IAC - 24 & $x$ & CIANO 79 & $7,8 \mathrm{ab}$ & $14,5 \mathrm{ab}$ & $47,3 \mathrm{ab}$ & $3,26 \mathrm{ab}$ & 3,45 & $8,8 \mathrm{ab}$ & $16,9 \mathrm{a}-\mathrm{c}$ & 52,9 & 3,12 & $3,50 \mathrm{c}$ \\
\hline 19 & CIANO 79 & $x$ & IAC - 24 & $5,2 \mathrm{~b}$ & $9,7 \mathrm{c}$ & $28,8 \mathrm{~b}$ & $2,98 \mathrm{ab}$ & 3,65 & $7,1 \mathrm{bc}$ & $14,5 \mathrm{bc}$ & 38,4 & 2,63 & $3,67 \mathrm{a}-\mathrm{c}$ \\
\hline 20 & CIANO 79 & $x$ & IAC - 24 & $6,6 \mathrm{ab}$ & $12,6 \mathrm{bc}$ & $41,3 \mathrm{ab}$ & $3,29 \mathrm{ab}$ & 3,63 & $7,0 \mathrm{c}$ & $14,2 \mathrm{c}$ & 40,2 & 2,79 & $3,68 \mathrm{a}-\mathrm{c}$ \\
\hline F (Anos) & - & - & - & - & - & - & - & - & $39,22^{*}$ & $5,41^{*}$ & $185,41^{*}$ & $235,48^{*}$ & $182,42^{*}$ \\
\hline F (Genótipos) & - & - & - & $2,02^{*}$ & $3,06^{*}$ & $3,23^{*}$ & $2,34^{*}$ & 0,83 & $3,04^{*}$ & $3,77^{*}$ & 2,00 & 1,84 & $5,25^{*}$ \\
\hline$F(G x A)$ & - & - & - & - & - & - & - & - & 1,57 & $1,78^{*}$ & $1,95^{*}$ & $2,57^{*}$ & 1,12 \\
\hline d.m.s. & - & - & - & 3,0 & 4,8 & 24,4 & 1,15 & 2,87 & 1,7 & 3,2 & 17,1 & 0,84 & 0,46 \\
\hline C.V. \% & - & - & - & 15,05 & 12,99 & 20,56 & 13,68 & 29,43 & 8,12 & 7,18 & 12,58 & 9,01 & 6,03 \\
\hline
\end{tabular}


Em relação à característica número de grão por espigueta, destacaram-se as linhagens diaplóides 6 , $7,12,13,14$ e 15 , que diferiram somente da cultivar IAC-24. Não se observaram diferenças significativas entre os genótipos em relação à massa de cem grãos.

Considerando o experimento de Capão Bonito (1998), as correlações simples calculadas apresentaram-se positivas e significativas entre as produções médias de grãos de cada genótipo e os respectivos comprimentos médios das espigas $\left(0,54^{*}\right)$, números médios de grãos por espiga $\left(0,70^{*}\right)$ e por espigueta $\left(0,63^{*}\right)$, e alturas médias de plantas $\left(0,80^{*}\right)$.

As correlações simples calculadas entre as produções médias de grãos de cada genótipo e os respectivos números médios de espiguetas por espiga e massas médias de cem grãos não foram significativas. Esses resultados sugerem que os genótipos mais adaptados (mais produtivos) às condições de solo ácido e cultivo de sequeiro apresentaram as plantas mais altas, com espigas mais compridas e maior número de grãos por espiga e por espigueta.

Os quadrados médios das análises conjuntas da variância para comprimento da espiga, número de espiguetas por espiga, números de grãos por espiga e por espigueta e massa de cem grãos dos genótipos dos experimentos de Tatuí (1997-1998) foram significativos para anos, genótipos (com exceção de números de grãos por espiga e por espigueta) e interação genótipos $\mathrm{x}$ anos (excetuando comprimento da espiga e massa de cem grãos), segundo o quadro 3.

As linhagens 6 e 14 apresentaram as espigas mais compridas, diferindo, porém, na média dos dois experimentos, somente das linhagens 19 e 20. Em relação ao número de espiguetas por espiga, a cultivar IAC-289 apresentou o maior valor, diferindo, das linhagens diaplóides 4, 5, 7, 11, 13, 15, 19 e 20. Não se observaram diferenças significativas entre os genótipos em relação ao número de grãos por espiga e por espigueta.

A cultivar IAC-289 revelou os grãos mais pesados, considerando os dois experimentos, não diferindo apenas da cultivar IAC-24 e das linhagens diaplóides 19 e 20. Por apresentar, ao mesmo tempo, maior número de espiguetas por espiga e grãos mais pesados, a cultivar IAC-289 revelou potencial para ser empregada como fonte genética dessas características no programa de cruzamentos do Instituto Agronômico.

Considerando os experimentos de Tatuí (19971998), as correlações simples calculadas apresentaram-se positivas e significativas entre as produções médias de grãos de cada genótipo e as respectivas massas médias de cem grãos $\left(0,70^{*}\right)$ e alturas médias de plantas $\left(0,51^{*}\right)$.
As correlações simples calculadas entre as produções médias de grãos de cada genótipo e os respectivos comprimentos médios das espigas, números médios de espiguetas por espiga, e números médios de grãos por espiga e por espigueta não foram significativas. Esses resultados sugerem que os genótipos mais adaptados (mais produtivos) às condições de solo corrigido e com irrigação por aspersão apresentaram as plantas mais altas (porte semi-anão) e os grãos mais pesados.

O quadro 4 apresenta o comprimento médio das raízes dos 20 genótipos de trigo avaliados, além das cultivares-controle BH-1146 (tolerante) e Anahuac (sensível), após 72 horas de crescimento em solução normal (sem alumínio), que se seguiu a um crescimento em solução-tratamento contendo seis diferentes concentrações de alumínio, referente à média de duas repetições.

Considerando-se $2 \mathrm{mg} . \mathrm{L}^{-1}$ de $\mathrm{Al}^{3+}$ (Quadro 4), verificou-se que a cultivar-controle Anahuac foi sensível a essa concentração de alumínio, ou seja, revelou paralisação irreversível do crescimento da raiz primária central após tratamento com $2 \mathrm{mg} . \mathrm{L}^{-1} \mathrm{de} \mathrm{Al}^{3+}$.

Todos os demais genótipos foram tolerantes, isto é, exibiram algum crescimento radicular após tratamentos em soluções contendo essa concentração de alumínio. O mesmo resultado foi observado quando foram adicionados $4 \mathrm{mg}$. $\mathrm{L}^{-1}$ de $\mathrm{Al}^{3+}$ nas soluções de tratamento.

A cultivar IAC-289 foi considerada sensível à concentração de $6 \mathrm{mg} \cdot \mathrm{L}^{-1}$ de $\mathrm{Al}^{3+}$ e os demais genótipos foram tolerantes a 6,8 e $10 \mathrm{mg} \cdot \mathrm{L}^{-1}$ de $\mathrm{Al}^{3+}$.

A alta tolerância da cultivar IAC-24 e a sensibilidade à toxicidade de $\mathrm{Al}^{3+}$ da 'IAC-289' obtidas neste trabalho estão de acordo com os resultados de CAmargo et al. (1995), pois essas cultivares apresentaram, respectivamente, altas e baixas produções médias de grãos, nos experimentos instalados em solo ácido de Capão Bonito, no período de 1997-1999.

Considerando os experimentos de Capão Bonito (1997-1999), as correlações simples calculadas apresentaram-se positivas e significativas entre as produções médias de grãos de cada genótipo e os respectivos crescimentos médios das raízes, medido após 72 horas de crescimento na solução nutritiva, que se seguiu ao crescimento na solução-tratamento contendo $2\left(0,65^{*}\right), 4\left(0,59^{*}\right), 6\left(0,51^{*}\right), 8\left(0,52^{*}\right)$ e $10\left(0,61^{*}\right)$ $\mathrm{mg} . \mathrm{L}^{-1}$ de $\mathrm{Al}^{3+}$. Esses resultados sugerem que os genótipos mais adaptados (mais produtivos) às condições de solo ácido e cultivo de sequeiro apresentaram-se tolerantes à toxicidade ao $\mathrm{Al}^{3+}$, em soluções nutritivas. 
Quadro 4. Comprimento médio das raízes $(\mathrm{mm})$ dos 20 genótipos de trigo avaliados após 72 horas de crescimento em solução normal, que se seguiu a um crescimento em solução tratamento contendo seis concentrações diferentes de alumínio

\begin{tabular}{|c|c|c|c|c|c|c|c|c|c|}
\hline \multirow{2}{*}{ Tratamento } & \multirow{2}{*}{\multicolumn{3}{|c|}{ Cruzamento }} & \multicolumn{6}{|c|}{ Concentração de alumínio (mg. $\left.\mathrm{L}^{-1}\right)$} \\
\hline & & & & \multirow{2}{*}{$\frac{0}{69,7}$} & \multirow{2}{*}{$\frac{2}{54,5}$} & \multirow{2}{*}{$\frac{4}{45,1}$} & \multirow{2}{*}{$\frac{6}{35,6}$} & \multirow{2}{*}{$\frac{8}{31,1}$} & \multirow{2}{*}{$\frac{10}{23,2}$} \\
\hline 1 & IAC - 24 & & & & & & & & \\
\hline 2 & IAC -289 & & & 65,8 & 22,8 & 1,0 & 0,0 & 0,0 & 0,0 \\
\hline 3 & CIANO 79 & $x$ & IAC -24 & 67,3 & 49,1 & 43,4 & 37,5 & 22,9 & 19,0 \\
\hline 4 & CIANO 79 & $X$ & IAC - 24 & 72,2 & 55,8 & 46,3 & 34,5 & 29,8 & 20,9 \\
\hline 5 & CIANO 79 & $x$ & IAC - 24 & 61,9 & 53,4 & 43,6 & 38,3 & 26,4 & 18,5 \\
\hline 6 & CIANO 79 & $X$ & IAC - 24 & 78,1 & 52,3 & 42,9 & 36,9 & 25,2 & 21,3 \\
\hline 7 & CIANO 79 & $x$ & IAC - 24 & 70,5 & 56,6 & 48,2 & 39,6 & 29,6 & 22,7 \\
\hline 8 & CIANO 79 & $x$ & IAC - 24 & 71,6 & 53,9 & 40,8 & 36,6 & 27,1 & 18,5 \\
\hline 9 & CIANO 79 & $x$ & IAC - 24 & 72,3 & 54,6 & 43,5 & 35,6 & 31,2 & 16,3 \\
\hline 10 & CIANO 79 & $x$ & IAC - 24 & 69,4 & 58,4 & 43,0 & 36,1 & 29,9 & 27,4 \\
\hline 11 & CIANO 79 & $x$ & IAC - 24 & 70,6 & 52,4 & 44,0 & 35,6 & 26,5 & 22,5 \\
\hline 12 & CIANO 79 & $x$ & IAC - 24 & 72,3 & 53,4 & 38,5 & 29,8 & 25,0 & 24,1 \\
\hline 13 & CIANO 79 & $x$ & IAC - 24 & 75,5 & 57,7 & 45,0 & 36,5 & 35,3 & 24,5 \\
\hline 14 & CIANO 79 & $x$ & IAC - 24 & 73,1 & 56,1 & 47,4 & 36,2 & 32,1 & 20,0 \\
\hline 15 & IAC - 24 & $x$ & CIANO 79 & 83,3 & 56,5 & 43,5 & 41,3 & 32,2 & 17,7 \\
\hline 16 & IAC - 24 & $x$ & CIANO 79 & 71,2 & 55,0 & 45,3 & 38,0 & 28,5 & 23,1 \\
\hline 17 & IAC - 24 & $x$ & CIANO 79 & 72,0 & 53,5 & 43,7 & 39,3 & 30,8 & 23,4 \\
\hline 18 & IAC - 24 & $x$ & CIANO 79 & 73,3 & 56,4 & 44,2 & 35,2 & 30,2 & 18,5 \\
\hline 19 & CIANO 79 & $x$ & IAC - 24 & 61,3 & 47,1 & 33,0 & 23,7 & 25,2 & 11,4 \\
\hline \multirow[t]{3}{*}{20} & CIANO 79 & $x$ & IAC - 24 & 63,2 & 46,5 & 31,7 & 17,5 & 21,1 & 10,8 \\
\hline & BH-1146 & & & 88,2 & 80,1 & 64,7 & 48,3 & 36,8 & 31,9 \\
\hline & Anahuac & & & 70,4 & 0,0 & 0,0 & 0,0 & 0,0 & 0,0 \\
\hline
\end{tabular}

Levando-se em consideração os experimentos de Tatuí (1997-2000), as correlações simples calculadas apresentaram-se não significativas entre as produções médias de grãos de cada genótipo e os respectivos crescimentos médios das raízes, medido após 72 horas de crescimento na solução nutritiva, que se seguiu ao crescimento na solução- tratamento contendo diferentes concentrações de $\mathrm{Al}^{3+}$. Esses resultados sugerem que os genótipos mais adaptados (mais produtivos) às condições de solo corrigido e com irrigação por aspersão independem do grau de tolerância à toxicidade de $\mathrm{Al}^{3+}$, em soluções nutritivas.

A cultivar IAC-24, tolerante à toxicidade de $\mathrm{Al}^{3+}$, foi uma das mais produtivas em solos corrigidos
(Tatuí) e solo ácido (Capão Bonito) (Quadros 1 e 4), discordando dos resultados de PRIOLI (1987), que demonstrou em milho, uma associação entre baixa produtividade e tolerância ao $\mathrm{Al}^{3+}$, quando os híbridos foram cultivados em solos de baixa acidez.

\section{CONCLUSÕES}

1. Os genótipos mais adaptados às condições de solo ácido e cultivo de sequeiro estão associados às plantas mais altas, com espigas mais compridas, com maior número de grãos por espiga e por espigueta e com tolerância à toxicidade de alumínio. 
2. Em solo ácido com aplicação de calcário e com irrigação por aspersão os genótipos mais produtivos estavam associados às plantas mais altas (porte semi-anão) com os grãos mais pesados, sem associação com a tolerância à toxicidade de alumínio.

3. A boa relação entre os resultados de campo com solo ácido e o excesso de $\mathrm{Al}^{3+}$ e os de laboratório para a tolerância à toxicidade de alumínio possibilitam a seleção de genótipos tolerantes ao alumínio em condição de laboratório.

4. O emprego da técnica de obtenção de linhagens $\mathrm{DH}$ foi altamente eficiente, tendo originado novos genótipos com características agronômicas vantajosas, em um período menor, em relação ao programa de melhoramento tradicional.

\section{AGRADECIMENTOS}

À Fundação de Amparo à Pesquisa do Estado de São Paulo (FAPESP) pelo apoio financeiro ao projeto e ao Conselho Nacional de Desenvolvimento Científico e Tecnológico (CNPq), pela concessão de bolsa de produtividade científica.

\section{REFERÊNCIAS BIBLIOGRÁFICAS}

CAMARGO, C.E.O. Melhoramento do trigo: Hereditariedade da tolerância a três concentrações de alumínio em solução nutritiva. Bragantia, Campinas, v.43, n.2, p.279-291, 1984.

CAMARGO, C.E.O. Trigo. In: FURLANI, A.M.C.; VIÉGAS, G.P. (Eds.). O melhoramento de plantas no Instituto Agronômico. Campinas: Instituto Agronômico, 1993. p.433-488.

CAMARGO, C.E.O.; FELICIO, J.C.; FERREIRA FILHO, A.W.P. Variedades de trigo para o Estado de São Paulo. Campinas: Instituto Agronômico, 1996. 20p. (Boletim Técnico, 163)

CAMARGO, C.E.O.; FERREIRA FILHO, A.W.P.São Paulo State Brazil Wheat Pool. In: BONJEAN, A.P.; ANGUS, W.J. (Eds.). The World Wheat Book: A History of Wheat Breeding. Paris, 2000. Cap. 21, p.549-577.
CAMARGO, C.E.O.; RAMOS, L.C.S.; FERREIRA FILHO, A.W.P.; TULMANN NETO, A. Anther culture and induced mutation for wheat improvement. In: PROSPECTS OF WHEAT GENETICS AND BREEDING FOR THE $21^{\text {ST }}$ CENTURY, 2001, Zhengzhou, China. In: International Wheat Genetics and Breeding Symposium. Proceedings... China Agricultural Scientech Press, 2001. p.137-145.

CAMARGO, C.E.O.; TULMANN-NETO, A.; FERREIRA-FILHO, A.W.P.; FREITAS, J.G.; PETTINELLI-JUNIOR, A.; CASTRO, J. L. Avaliação de genótipos oriundos de cruzamento interespecífico e radiação gama no Estado de São Paulo. Scientia Agricola, Piracicaba, v.58, n.1, p. 25-37, 1995.

GRANDO, M.F.; MORAES-FERNANDES, M.I.B. Two point deterministic model for acquisition of in vitro pollen grain androgenetic capacity based on wheat studies. Brazilian Journal of Genetics, Ribeirão Preto, v.20, n.3, p.467-476, 1997.

MEHTA, Y.R. Doenças do trigo e seu controle. São Paulo: Agronômica Ceres, 1978. 190p.

MOORE, D. P.; KRONSTAD, W. E.; METZGER, R. J. Screening wheat for aluminum tolerance. In: WORKSHOP ON PLANT ADAPTATION TO MINERAL STRESS IN PROBLEM SOILS, 1976, BELTSVILLE. Proceedings... Ithaca: Cornell University, 1976. p.287-295.

PRIOLI, A. J. Análise genética da tolerância à acidez do alumínio em milho (Zea mays L.). 1987. 182f. Tese (Doutorado) - Instituto de Biologia/Universidade Estadual de Campinas.

RAMOS, L.C.S.; YOKOO, E.Y.; CAMARGO, C.E.O. Adequação de meios de cultura de anteras e testes de genótipos de trigo. Bragantia, Campinas, v.53, n.2, p.151-157, 1994.

RAMOS, L.C.S.; CAMARGO, C.E.O.; FERREIRA FILHO, A.W.P.; YOKOO, E.Y.; CASTRO, J.L.; PETTINELLI JUNIOR, A.; SILVA, M.R. Linhagens diaplóides de trigo obtidas via cultura de anteras. Scientia Agricola, Piracicaba, v.57, n.1, p.177-183, 2000.

SALOMON, M.V.; CAMARGO, C.E.O.; PETTINELLIJUNIOR, A.; AZEVEDO FILHO, J A. Performance of dihaploid wheat lines obtained via anther culture. Scientia Agricola, Piracicaba, v.60, n.1, p. 43-50, 2003.

SCHRAMM, W.; FULCO, W. S.; SOARES, M. H. G.; ALMEIDA, A. Resistência de cultivares de trigo em experimentação ou cultivo no Rio Grande do Sul, às principais doenças fúngicas. Agronomia Sulriograndense, Porto Alegre, v.10, n.1, p.31-52, 1974. 